\title{
El abismo que separa la Constitución de 1991 y los indígenas que habitan en Bogotá, D.C.,... veinte años después ${ }^{* 1}$
}

\author{
The Constitution of 1991 and the \\ indigenous people that live in Bogotá. \\ Twenty years later.
}

Fecha de recepción: 6 de abril de 2011 Fecha de evaluación: 20 de junio de 2011 Fecha de aprobación:21 de junio de 2011

\author{
AlFONSO FAJARDO**
}

\section{Resumen}

Los estudios socio-jurídicos hacen especial énfasis en analizar el impacto de las normas jurídicas en la vida y la cotidianidad de los actores sociales. En este caso, al evaluar el impacto de la Constitución Política, veinte (20) años después de su aprobación por parte de la ANC, respecto de los derechos de los pueblos indígenas, no basta con estudiar la amplia y generosa jurisprudencia de la Corte Constitucional sobre este tema; tenemos que estudiar las políticas públicas, los planes y programas que establecen de manera clara los compromisos y recursos asignados en el marco de los planes de desarrollo nacionales y municipales, que permiten asegurar el goce y disfrute de Estados de derecho que tan ampliamente consagró la Carta Magna y los instrumentos internacionales de protección de derechos humanos para nuestros pueblos originarios.

\footnotetext{
Artículo de reflexión.

1 Agradezco al candidato a Magíster Heyder Alfonso Camelo su apoyo en la redacción del borrador inicial de este artículo. Igualmente, al doctor Luis Carlos Osorio Rendón, Personero Delegado para Asuntos de Gobierno de Bogotá y a la doctora María del Pilar Valencia, Asesora del Despacho del señor Personero de Bogotá.

** Doctor en Derecho, Programa de Derechos Fundamentales de la Universidad Carlos III de Madrid. Doctor en Sociología y Ciencias Políticas de la Universidad Complutense de Madrid, España. Magíster en Teorías Críticas del Derecho, de la Universidad Internacional de Andalucía, España. Diplomado en Derecho Internacional Humanitario en el Instituto de San Remo, Italia. Diploma Internacional en Derechos Humanos Universidad de Ginebra, Suiza; Diploma de Derecho Internacional de los Derechos Humanos en Estrasburgo, Francia; Especialista en Derechos Humanos y DIH de la ESAP. Abogado. Consultor de la ONU y de varias organizaciones nacionales e internacionales de Derechos Humanos, Derecho Internacional Humanitario (DIH), mecanismos alternativos de solución de conflictos y justicia comunitaria; ex Consultor del Programa Presidencial de Derechos Humanos de la Vicepresidencia de la República, ex asesor de la Dirección de Derechos Humanos y Apoyo a la Justicia de la Secretaría de Gobierno (Alcaldía Mayor de Bogotá) y actualmente Director de la Maestría en Derechos Humanos y DIH de la Facultad de Derecho de la Universidad Santo Tomás y coordinador de múltiples diplomados y procesos de formación en DIH a comunidades y organizaciones sociales. En la actualidad, está realizando sus estudios posdoctorales, en Convenio con la Universidad de Córdoba, Argentina, y la USTA.
} 
Igualmente, el Distrito Capital se tardó veinte (20) años en aprobar, mediante Acuerdo 359 de 2009 “Por el cual se establecen los lineamientos de política pública para los indígenas en Bogotá, D.C., y se dictan otras disposiciones", lo que puede ser el inicio para la creación de una verdadera política pública para los pueblos indígenas que habitan la capital de la República.

El abismo que separa la proclamación de los derechos en la Constitución de 1991 y la garantía y disfrute de los mismos es, sin duda alguna, las políticas públicas. Entonces, analizaremos en este artículo esos programas de la administración municipal que intentan satisfacer las demandas de nuestros pueblos originarios y la percepción que tienen los indígenas beneficiarios de estos programas; es decir, se hará un balance sobre su aplicación.

Palabras clave: Constitución de 1991, pueblos indígenas del Distrito Capital, políticas públicas diferenciales, Acuerdo 359 de 2009

\begin{abstract}
Socio-juridical studies make a special emphasis on analyzing the impact of the juridical norms on the daily life of social actors. In this case, when evaluating the impact of the constitution, 20 years after its approval by the ANC, according to the rights of the indigenous people, it is not enough to study the wide and generous jurisprudence of the constitutional court on this topic; we have to study the public policies, the plans, and programs that establish in a clear way the compromises and resources allocated in the frame of the national and municipal development plans that ensure the enjoyment and benefits of the appliance of states of right that were so widely consecrated by the Carta Magna and the international instruments for the protection of human rights, for our originary people.
\end{abstract}

In the same way the capital district took 20 years to approve the 359 agreement of 2009 "by which the alignments of public policy for indigenous people in Bogota D.C. and other dispositions are established", this could be the beginning of the creation of a true public policy for the indigenous people that live in the capital city.

The abyss that separates the proclamation of the rights in the 1991 constitution and the guarantee and enjoyment of these is without a doubt, the public policies. We shall analyze in this article, those programs of the municipal administration which try to satisfy the requests from our originary people; we shall also analyze the perception that the beneficiary indigenous people have on this programs and the balance of their application.

Keywords: Constitution of 1991, indigenous people of the Capital District, differential public policy, Agreement 359 of 2009 


\section{INTRODUCCIÓN}

La Constitución Política de Colombia cumple veinte años; los balances son numerosos desde las más variadas disciplinas, pero no todos son optimistas.

Respecto de los derechos de los pueblos indígenas, la euforia de la sociedad colombiana ante su proclamación en el plano constitucional que, tras una lucha de resistencia cinco veces centenaria, se convirtió progresivamente en una gran frustración. Sí, muchas cosas han cambiado en Colombia para los pueblos indígenas; uno de los ejemplos más destacados es la amplia y variada jurisprudencia que emitió la Corte Constitucional para garantizar los derechos de los pueblos originarios del país. Sin embargo, la misma Corte ha tenido que señalar, por ejemplo, mediante el Auto 004 del 2009, en el marco de la superación del Estado de cosas inconstitucional declarado mediante Sentencia T-025 de 2004, la grave crisis social y humanitaria de nuestros pueblos indígenas, treinta de ellos al borde de la extinción física y cultural (Fajardo, 2010).

La distancia que separa los preceptos constitucionales y la realidad de los actores sociales, en este caso los pueblos indígenas, son las políticas públicas, los planes y programas diseñados e implementados para garantizar la vigencia y restablecimiento de los derechos proclamados en la Constitución (Abramovich y Pautassi, 2010). Esto implica la asignación de recursos humanos, financieros, logísticos, etc.; por eso, uno de los criterios para medir el impacto real de estos veinte años de constitución es analizando las políticas públicas, los planes, programas, acciones afirmativas y todo tipo de garantías que permitan materializar los derechos, en este caso, de los pueblos indígenas.

Solo después de veinte años, en la ciudad de Bogotá se aprueba, por primera vez en el país, un instrumento de desarrollo municipal para garantizar la vigencia y el respeto de los derechos de estos pueblos. Fue justamente mediante el Acuerdo 359 del 2009, "Por el cual se establecen los lineamientos de política pública para los indígenas en Bogotá, D.C., y se dictan otras disposiciones"; sin embargo, aún no se ha aprobado un plan de acciones afirmativas que permita desarrollar y asegurar los recursos para los pueblos indígenas que habitan el Distrito Capital, como una posibilidad para materializar los derechos reivindicados durante más de quinientos años de resistencia.

\section{PROTECCIÓN INTERNACIONAL DE LOS DERECHOS DE LOS PUEBLOS INDÍGENAS}

Los instrumentos internacionales en materia de protección de los derechos de los pueblos indígenas tienen en el Convenio 169 de la Organización Internacional del Trabajo (OIT), aprobado por el Congreso colombiano mediante Ley $21 \mathrm{de}$ 1991, un fundamento jurídicamente vinculante que permite el reconocimiento de "las aspiraciones de esos pueblos a asumir el control de sus propias instituciones y formas de vida y de su desarrollo económico, y a mantener y fortalecer sus identidades, lenguas y religiones, dentro del marco de los Estados en que viven"; para esto dispone:

Los gobiernos deberán asumir la responsabilidad de desarrollar, con la participación de los pueblos interesados, una acción coordinada y sistemática con miras a proteger los derechos de esos pueblos y a garantizar el respeto de su integridad.

Igualmente, de un trabajo de veinte años, al fin se aprueba en el año 2007 la Declaración de Naciones Unidas sobre los derechos de los pueblos indígenas (ONU, 2007); la necesidad de este instrumento reside en que:

Afirmando que los pueblos indígenas son iguales a todos los demás pueblos y reconociendo al mismo tiempo el derecho de todos los pueblos a ser diferentes, a considerarse a sí mismos diferentes $y$ a ser respetados como tales, [...] 
Reafirmando que, en el ejercicio de sus derechos, los pueblos indígenas deben estar libres de toda forma de discriminación, [...].

Al reconocer los altos niveles de discriminación y vulnerabilidad en los que se encuentran los pueblos indígenas, la Declaración ha reafirmado:

Los indígenas tienen derecho, como pueblos o como personas, al disfrute pleno de todos los derechos humanos y las libertades fundamentales reconocidos por la Carta de las Naciones Unidas, la Declaración Universal de Derechos Humanos y la normativa internacional de los derechos humanos.

La importancia que se da en el plano internacional a la protección de los pueblos indígenas se hace manifiesta en el informe que el relator especial desarrolló para el año 2004 en relación con la realidad del país (ONU, 2004). En él visibiliza los efectos del conflicto armado, prolongado en los pueblos indígenas, que han sufrido asesinatos y torturas, desplazamientos masivos, desapariciones forzadas, reclutamiento involuntario de jóvenes a unidades combatientes, violaciones de mujeres y ocupación de sus territorios por parte de grupos guerrilleros, paramilitares y otros actores armados ilícitos. En este sentido, el Informe de Rodolfo Stavenhagen sostenía:

La violencia política contra los indígenas se incrementó en los años noventa y viene generando una creciente resistencia a la guerra. En los últimos quince años se registraron más de 2.660 casos de violaciones a los derechos humanos y al derecho internacional humanitario contra pueblos indígenas. Estos actos de violencia son imputables ante todo a las guerrillas y a las AUC (grupos paramilitares que han sido vinculados al ejército $y$ a autoridades gubernamentales). La tasa de violencia es $\mathbf{1 0 0 \%}$ mayor a la media nacional en los municipios indígenas, siendo los más afectados los pueblos Kankuamo y Wiwa de la Sierra Nevada, el pueblo Kofán en Putumayo, el Chimila en Magdalena, así como los pueblos
Korebajú, Betoyes y Nasa, y los Tule y Embera-katío en la región de Urabá.

Para verificar el cumplimiento de las recomendaciones del señor Rodolfo Stavenhagen, en el año 2009 visita el país el relator especial señor James Anaya, quien tomó como punto de partida lo dicho por el anterior informe e inició una evaluación de las condiciones actuales de los pueblos indígenas. En este informe (ONU, 2010) sostiene:

Los derechos de los pueblos indígenas siguen siendo amenazados y vulnerados, y es indudable que el conflicto armado interno y sus efectos contribuyen a esta grave situación. Según casi todos los indicadores, el conflicto armado afecta de manera desproporcionada a los pueblos indígenas del país. La localización estratégica de los territorios de los pueblos indígenas, tanto para el desarrollo de la confrontación armada como para las actividades del narcotráfico, los hacen particularmente vulnerables.

[...] El desplazamiento forzado de los pueblos indígenas amenaza su sobrevivencia cultural y física, tal como ha señalado la Corte Constitucional, y conlleva situaciones humanitarias críticas como hacinamiento, insalubridad y falta de alimentación. Las autoridades públicas no se encuentran preparadas para responder adecuadamente a las necesidades humanitarias de las víctimas $y$, en particular, de las mujeres, niñas y niños. Es de gran preocupación el agudo impacto del desplazamiento forzado en las mujeres indígenas, que según la Corte Constitucional son entre los segmentos poblacionales que han sido afectados "con mayor dureza por los crímenes, las injusticias e inequidades que forman parte constitutiva tanto de la violencia armada como del desplazamiento forzado".

La realidad encontrada por el relator especial James Anaya en el país es de gran preocupación en la medida que, a pesar de reconocer determinadas acciones por parte del gobierno nacional, las múltiples indicaciones que evidencia la grave situación de los pueblos indígenas verifican que esta no se 
ha afrontado con la urgencia que la gravedad de la situación merece.

El relator especial entrega al Estado Colombiano una serie de recomendaciones encaminadas a otorgar una efectiva protección de los derechos humanos de los pueblos indígenas; el relator recomienda al Estado colombiano:

El Estado y los grupos armados tienen la obligación de cumplir en todo momento con el derecho internacional humanitario y respetar los derechos humanos. Se sugiere el establecimiento de una comisión amplia independiente para vigilar su plena aplicación.

La población indígena desplazada, en particular las mujeres y los niños, debe recibir atención prioritaria por parte del Estado y de los organismos internacionales. Especial atención deberán recibir las mujeres y en particular las madres de familia.

Es urgente asegurar la provisión de alimentos a comunidades indígenas y en particular a las poblaciones desplazadas en zonas de conflicto y asegurar el libre tránsito de ayuda alimenticia a los grupos más necesitados.

Deberán expedirse a la mayor brevedad posible las leyes reglamentarias necesarias para implementar adecuada y efectivamente las disposiciones constitucionales en materia de derechos humanos de los pueblos indígenas.

Se establezca un mecanismo eficaz para la protección y promoción de los derechos de la mujer indígena en el país, dirigido a la prevención de posibles violaciones de sus derechos fundamentales y a potenciar su activa participación en decisiones que afectan sus vidas.

La fiscalía deberá investigar y aplicar la ley a todas las denuncias relativas a abusos y violaciones cometidas por miembros de las fuerzas armadas y la Policía Nacional contra miembros de comunidades indígenas.

Las instancias del Estado correspondientes deberán cumplir inmediatamente y sin excepción las medidas cautelares que la Comisión Interamericana de Derechos Humanos ha definido para los diferentes pueblos indígenas.

En los planes de educación pública y gratuita (obligación del Estado) deberá consolidarse el programa de educación bilingüe e intercultural en zonas indígenas, y las entidades privadas dedicadas a la educación deberán hacerlo solamente como complementarias a la acción del Estado.

Los planes del gobierno de dar cobertura de servicios de salud a toda la población indígena deberán tomar en cuenta y brindar protección a la medicina tradicional y sus practicantes en las comunidades indígenas.

\section{LOS PUEBLOS INDÍGENAS COLOMBIANOS Y EL SISTEMA INTERAMERICANO DE DERECHOS HUMANOS}

Otro escenario internacional donde se ha ventilado la situación de los pueblos indígenas de Colombia es el sistema interamericano de derechos humanos. La Comisión Interamericana de Derechos Humanos (CIDH) no ha sido ajena a la denuncia y promoción del pleno disfrute de estos derechos para los pueblos indígenas, observando la vigencia general de aquellos en los Estados miembros. Como lo ha señalado el profesor Ariza Santamaría, respecto de los derechos de los pueblos indígenas existen muchas promesas sin cumplir y pareciera que el horizonte no es nada optimista sobre su futuro cumplimiento (Ariza, 2010).

Estas funciones y atribuciones han generado el Informe anual de derechos humanos para el año 2009, donde se expresa la preocupación por las dificultades en el cumplimiento de las recomendaciones, así como en el de las sentencias y medidas provisionales de la Corte Interamericana, en casos donde la o las víctimas son miembros de un pueblo indígena. Al respecto, la Comisión insta a los Estados a redoblar sus esfuerzos por cumplir con las decisiones de las instituciones 
interamericanas que afectan a los pueblos indígenas (Comisión Interamericana de Derechos Humanos, 2009). Con ello no sólo se reconoce, protege y repara a grupos específicos de personas, sino que también se respeta una forma especial de vida y la diversidad humana que hace parte inherente de las sociedades del continente americano (Fajardo, 2004).

La CIDH es clara en afirmar que a lo largo del año recibió información sobre actos de violencia contra los pueblos indígenas. La ONIC denunció que entre enero y mayo de 2009 se registraron 56 homicidios contra indígenas, lo cual representa una variación del $124 \%$ con relación al mismo periodo en el año 2008. En sus observaciones, el Estado indicó que las denuncias recibidas se tramitaron y que se han iniciado acciones conjuntas entre las instituciones gubernamentales a fin de salvaguardar los derechos especiales de los pueblos indígenas. Asimismo, indicó que la Unidad Nacional de Derechos Humanos de la Fiscalía General de la Nación realiza un seguimiento especial y que a la fecha tiene asignadas 182 investigaciones, producto de las cuales se condenaron a 168 personas a través de dieciséis sentencias.

En consecuencia, la CIDH, a lo largo de la última década, para Colombia ha generado una serie de medidas cautelares que procuran la protección de pueblos indígenas que poseen riesgos en su seguridad y latentes violaciones a sus derechos. Han sido beneficiarios de estas medidas los pueblos indígenas Wiwa de la Sierra Nevada de Santa Marta, Nasa, Embera Chami y Wayuu, entre otros.

Tabla 1.

\begin{tabular}{|c|c|c|}
\hline Beneficiarios & Hechos & Medidas decretadas \\
\hline $\begin{array}{l}2010 \text { - } 87 \text { familias de la comuni- } \\
\text { dad Alto Guayabal-Coredocito, } \\
\text { del pueblo Emberá, declarada } \\
\text { "So Bia Drua" - área humanitaria, } \\
\text { del resguardo indígena Uradá } \\
\text { Jiguamiandó, municipio de Car- } \\
\text { men del Darién, departamento } \\
\text { de Chocó. }\end{array}$ & $\begin{array}{l}\text { Esta comunidad habría sido ob- } \\
\text { jeto de actos de violencia que } \\
\text { pusieron en riesgo sus vidas e } \\
\text { integridad personal. Se alega, } \\
\text { entre otros hechos, que el } 30 \\
\text { de enero de } 2010 \text { dos helicóp- } \\
\text { teros y un avión de las fuerzas } \\
\text { armadas habría realizado un } \\
\text { ametrallamiento y bombardeo } \\
\text { a } 300 \text { metros del asentamiento } \\
\text { principal de la comunidad, dando } \\
\text { con la casa de una familia donde } \\
\text { se encontraban tres adultosy dos } \\
\text { niños, que resultaron heridos. }\end{array}$ & $\begin{array}{l}\text { La Comisión Interamericana so- } \\
\text { licitó al Estado de Colombia que } \\
\text { adopte las medidas necesarias a } \\
\text { fin de proteger la vida e integri- } \\
\text { dad personal de } 87 \text { familias de la } \\
\text { comunidad Alto Guayabal - Core- } \\
\text { docito; que concierte las medidas } \\
\text { por adoptarse con los beneficia- } \\
\text { rios y sus representantes, y que } \\
\text { informe sobre las acciones de } \\
\text { investigación adoptadas respecto } \\
\text { de los hechos que dieron lugar a } \\
\text { la adopción de medidas cautela- } \\
\text { res a fin de remover los factores } \\
\text { de riesgo para los beneficiarios. }\end{array}$ \\
\hline
\end{tabular}




\begin{tabular}{|c|c|c|}
\hline Beneficiarios & Hechos & Medidas decretadas \\
\hline $\begin{array}{l}\text { El } 14 \text { de enero de } 2009 \text { la CIDH } \\
\text { otorgó medidas cautelares a fa- } \\
\text { vor de } 32 \text { dirigentes y asesores } \\
\text { del Consejo Regional Indígena } \\
\text { del Cauca (CRIC). }\end{array}$ & $\begin{array}{l}\text { Se alega que los dirigentes y } \\
\text { asesores del CRIC serían blancos } \\
\text { de actos de violencia, amenaza } \\
\text { y estigmatización por causa de } \\
\text { sus actividades como líderes } \\
\text { indígenas. Asimismo, se alega } \\
\text { que desde agosto de } 2008 \text { se } \\
\text { habrían incrementado los ho- } \\
\text { micidios, amenazas y actos de } \\
\text { hostigamiento contra la dirigen- } \\
\text { cia del CRIC, y se hace referencia } \\
\text { entre otras a la muerte de Edwin } \\
\text { Legarda Vásquez, esposo de la } \\
\text { Consejera Mayor del CRIC, Aída } \\
\text { Marina Quilcué Vivas. }\end{array}$ & $\begin{array}{l}\text { La Comisión Interamericana soli- } \\
\text { citó al Estado colombiano adop- } \\
\text { tar las medidas necesarias para } \\
\text { garantizar la vida y la integridad } \\
\text { personal de los beneficiarios, así } \\
\text { como informar sobre las acciones } \\
\text { adoptadas a fin de remover los } \\
\text { factores de riesgo que justifican } \\
\text { la adopción de estas medidas } \\
\text { cautelares. La Comisión con- } \\
\text { tinúa dando seguimiento a la } \\
\text { situación. }\end{array}$ \\
\hline $\begin{array}{l}\text { El } 4 \text { de febrero de } 2005 \text { la CIDH } \\
\text { otorgó medidas cautelares a fa- } \\
\text { vor de los miembros del pueblo } \\
\text { indígena Wiwa de la Sierra Neva- } \\
\text { da de Santa Marta. }\end{array}$ & $\begin{array}{l}\text { Durante los últimos dos años } \\
\text { este pueblo indígena ha sido } \\
\text { víctima de una serie de actos de } \\
\text { violencia paramilitar, incluyendo } \\
\text { el asesinato de aproximada- } \\
\text { mente } 50 \text { líderes indígenas, el } \\
\text { desplazamiento forzado de más } \\
\text { de } 800 \text { personas y la afectación } \\
\text { de la situación humanitaria de } \\
\text { las comunidades de La Laguna, } \\
\text { El Limón, Marokazo, Dudka, } \\
\text { Linda y Potrerito. Se alega que } \\
\text { el } 19 \text { de enero de } 2005 \text { fueron } \\
\text { asesinados el Tesorero General } \\
\text { de la Organización Wiwa Yu- } \\
\text { gumaiun Bukuanarúa Tayrona, } \\
\text { Ángel Milciades Loperena Díaz } \\
\text { y su hermano Darío Loperena, } \\
\text { maestro de la comunidad, en San } \\
\text { Juan del Cesar (departamento de } \\
\text { La Guajira), habiéndose atribuido } \\
\text { responsabilidad al Bloque Norte } \\
\text { de las Autodefensas Unidas de } \\
\text { Colombia, bajo el mando de } \\
\text { "Jorge 40". }\end{array}$ & $\begin{array}{l}\text { La Comisión solicitó al Estado } \\
\text { colombiano la adopción de las } \\
\text { medidas necesarias para proteger } \\
\text { la vida y la integridad personal de } \\
\text { los miembros del pueblo Wiwa } \\
\text { de la Sierra Nevada de Santa } \\
\text { Marta, respetando su identidad } \\
\text { cultural y protegiendo la especial } \\
\text { relación que tienen con su territo- } \\
\text { rio, conforme a las obligaciones } \\
\text { contraídas por el Estado; brindar } \\
\text { atención humanitaria a las vícti- } \\
\text { mas de desplazamiento y de la } \\
\text { crisis alimentaria, en particular a } \\
\text { las niñas y niños del pueblo indí- } \\
\text { gena; concertar las medidas de } \\
\text { protección colectiva, incluyendo } \\
\text { la presencia de un defensor co- } \\
\text { munitario, con los beneficiarios, } \\
\text { a través de sus organizaciones } \\
\text { representativas Wiwa Yugumaiun } \\
\text { Bukuanarúa Tayrona OBYBT y } \\
\text { la Organización Gonawindua } \\
\text { Tayrona y los peticionarios; adop- } \\
\text { tar las medidas necesarias a fin } \\
\text { de poner término a los hechos } \\
\text { de violencia y las amenazas pro- } \\
\text { feridas en contra de la comunidad } \\
\text { beneficiaria. }\end{array}$ \\
\hline
\end{tabular}




\begin{tabular}{|c|c|c|}
\hline Beneficiarios & Hechos & Medidas decretadas \\
\hline $\begin{array}{l}\text { El } 31 \text { de octubre de } 2005 \text { la Comi- } \\
\text { sión otorgó medidas cautelares } \\
\text { a favor de Arquímedes Vitonás, } \\
\text { Ezequiel Vitonás, Gilberto Muñoz } \\
\text { Coronado; Gabriel Pavi, Nelson } \\
\text { Lemus, Plinio Tróchez, Miliciades } \\
\text { Musice, Oscar Cuchillo y Alciades } \\
\text { Escué, líderes de la Asociación } \\
\text { de Cabildos del Norte del Cauca. }\end{array}$ & $\begin{array}{l}\text { La información provista indica } \\
\text { que el pueblo Nasa que habita } \\
\text { en el norte del departamento } \\
\text { del Cauca, y en particular sus } \\
\text { líderes, habrían sido objeto de } \\
\text { actos de violencia y amenazas } \\
\text { por los actores del conflicto ar- } \\
\text { mado asentados en esa zona, } \\
\text { así como de señalamientos del } \\
\text { Ejército Nacional. }\end{array}$ & $\begin{array}{l}\text { La Comisión solicitó al Gobier- } \\
\text { no colombiano la adopción de } \\
\text { las medidas necesarias para } \\
\text { proteger la vida y la integridad } \\
\text { personal de Arquímedes Vito- } \\
\text { nás, Ezequiel Vitonás, Gilberto } \\
\text { Muñoz Coronado, Gabriel Pavi, } \\
\text { Nelson Lemus, Plinio Tróchez, } \\
\text { Miliciades Musice, Oscar Cuchillo } \\
\text { y Alciades Escué e informar sobre } \\
\text { las acciones adoptadas con el } \\
\text { fin de investigar los hechos que } \\
\text { justifican la adopción de medidas } \\
\text { cautelares. }\end{array}$ \\
\hline $\begin{array}{l}\text { El } 23 \text { de septiembre de } 2004 \text { la } \\
\text { CIDH otorgó medidas cautelares } \\
\text { a favor de Mariana Epinayú, Car- } \\
\text { men Cuadrado Fincé, Débora Ba- } \\
\text { rros y Karmen Ramírez, liderezas } \\
\text { del pueblo indígena Wayúu en el } \\
\text { departamento de La Guajira. }\end{array}$ & $\begin{array}{l}\text { La información disponible indica } \\
\text { que durante los últimos tres años } \\
\text { la comunidad indígena Wayúu ha } \\
\text { padecido actos de violencia por } \\
\text { parte de grupos paramilitares } \\
\text { comandados por "Jorge } 40 \text { ", con } \\
\text { la colaboración o aquiescencia } \\
\text { de agentes del Estado. Los peti- } \\
\text { cionarios alegan que algunas de } \\
\text { las llamadas "liderezas" (voceras } \\
\text { de las familias Wayúu ante los } \\
\text { organismos nacionales e interna- } \\
\text { cionales) han sido objeto de ame- } \\
\text { nazas contra su vida e integridad } \\
\text { personal como resultado de su } \\
\text { actividad de denuncia. Entre ellas } \\
\text { se destacan Mariana Epinayú, } \\
\text { Carmen Cuadrado Fince, Débora } \\
\text { Barros Fince y Karmen Ramírez } \\
\text { Boscán, liderezas y familiares de } \\
\text { indígenas asesinados y desapare- } \\
\text { cidos en una masacre perpetrada } \\
\text { el } 18 \text { de abril de } 2004, \text { quienes } \\
\text { han sido blanco de amenazas y } \\
\text { actos de hostigamiento. }\end{array}$ & $\begin{array}{l}\text { La Comisión solicitó al Gobierno } \\
\text { colombiano la adopción de las } \\
\text { medidas necesarias para garan- } \\
\text { tizar la vida y la integridad física } \\
\text { de Mariana Epinayú, Carmen } \\
\text { Cuadrado Fincé, Débora Barros, } \\
\text { y Karmen Ramírez, e informar so- } \\
\text { bre las acciones adoptadas a fin } \\
\text { de poner término a la situación } \\
\text { que justifican la adopción de me- } \\
\text { didas cautelares, incluyendo los } \\
\text { procesos judiciales que resulten } \\
\text { pertinentes. El } 16 \text { de noviembre } \\
\text { de } 2004 \text { la CIDH amplió la vigen- } \\
\text { cia de las medidas cautelares } \\
\text { a fin de cobijar a Roland Fince } \\
\text { Uriana, Ana Julia Fince Uriana, } \\
\text { Telemina Barros Cuadrado, José } \\
\text { Miguel Barros Fince y Katty Fince } \\
\text { Uriana. }\end{array}$ \\
\hline
\end{tabular}




\section{1 ¿UNA CONSTITUCIÓN EN CLAVE INTERCULTURAL?}

Con la expedición de la Constitución Nacional de 1991, Colombia se reconoce como una nación pluriétnica y pluricultural, como lo plasma el artículo 70: "El Estado reconoce y protege la diversidad étnica y cultural de la Nación colombiana"; esta disposición se basa en la intención del Constituyente de terminar con la tutela de los indígenas por parte del Estado. La Corte Constitucional determina el área de aplicación del artículo $7^{\circ}$ de la $\mathrm{CP}$ en el caso concreto, ponderándolo con otros principios constitucionales que poseen un peso comparable. Ubica el principio de la diversidad étnica y cultural en una relación directa con los principios de democracia y pluralismo (preámbulo, artículos $1^{\circ}$ y $2^{\circ}$ de la $\mathrm{CP}$ ), señalando que se trata de una manifestación de la estructura pluralista del Estado colombiano. En el principio de la diversidad étnica y cultural quedaría establecido el estatus especial para las comunidades indígenas, el cual se manifestaría en el ejercicio de los derechos de legislación y jurisprudencia dentro de su área territorial, en coincidencia con sus propios valores culturales (artículo 246 de la CP), de la autogestión mediante poderes propios dentro de sus usos $y$ costumbres (artículo 330 de la CP), la creación de distritos electorales especiales para senadores y diputados indígenas (artículos 171 y 176 de la CP) y el ejercicio irrestricto de la propiedad sobre sus resguardos y territorios (Semper, 2007). En el marco constitucional es importante mencionar los artículos 10, 10, 70, 329, y los transitorios 55 y 56, así como el artículo 13 sobre derecho a la igualdad y la obligación del Estado de adoptar medidas especiales para la población más vulnerable (principal fundamento de las acciones afirmativas, antes conocidas como discriminación positiva) (Fajardo, 1998).

La situación de los derechos de los pueblos indígenas, como ha sido señalado por organismos internacionales de protección de derechos hu- manos, dista de ser óptima, pues se presenta un constante hostigamiento y victimización de sus miembros como resultado de las dinámicas propias del conflicto armado interno; se han procurado en el ordenamiento interno estrategias y medidas de protección y conservación del acerbo cultural de estos pueblos con miras a la garantía efectiva de sus derechos. Uno de los fenómenos que mayor incidencia tiene como resultado de las confrontaciones y el ataque directo a la población civil es el desplazamiento, el cual afecta en alto grado a las comunidades indígenas por su especial condición de vulnerabilidad y por la búsqueda de colaboración de expropiación de la tierra (Fajardo, 2008).

La honorable Corte Constitucional ha sido el ente encargado de generar marcos de protección de avanzada en cuanto a temas de violación de derechos humanos se trata. Esta Corte, a través de su Sentencia T-025 de 2004, declara el Estado de cosas inconstitucional respecto de la situación de la población en situación de desplazamiento forzado, caracterizado por una continua, masiva y sistemática vulneración de sus derechos fundamentales, que el mismo legislador reconoció al definir la condición de desplazado y que confirmó por el volumen de acciones de tutela presentadas por las personas desplazadas para acceder a las diferentes ayudas estatales; por la prolongada omisión de las autoridades en el cumplimiento de sus obligaciones para garantizar los derechos; por la no expedición de medidas legislativas, administrativas o presupuestales necesarias para evitar la vulneración de derechos, y por la existencia de un problema social cuya solución compromete la intervención de varias entidades, que requiere la adopción de un conjunto complejo y coordinado de acciones, y que exige un nivel de recursos que demanda un esfuerzo presupuestal importante por parte del Estado

En el desarrollo de la sentencia en comento, la Corte Constitucional profiere el Auto 004 de 2009, el cual hace referencia a la protección de 
los derechos fundamentales de las personas y los pueblos indígenas desplazados por el conflicto armado o en riesgo de desplazamiento forzado, abordando el mayor riesgo al cual se encuentran expuestos estos pueblos: el del exterminio de algunas comunidades, sea desde el punto de vista cultural en razón al desplazamiento y dispersión de sus miembros, como desde el punto de vista físico debido a la muerte natural o violenta de sus integrantes. La Corte sostiene que, en el curso de la última década, el conflicto armado que se desarrolla en Colombia, reorientado por actividades relacionadas con el narcotráfico, se convirtió en el principal factor de riesgo para la existencia misma de docenas de comunidades y pueblos indígenas a lo largo del territorio nacional (Carvajal, 2008).

Los grupos indígenas colombianos están particularmente indefensos y expuestos al conflicto armado y sus consecuencias, sobre todo el desplazamiento. Deben soportar los peligros inherentes a la confrontación sobre la base de situaciones estructurales preexistentes de pobreza extrema y abandono institucional, que operan como factores catalizadores de las profundas violaciones de derechos humanos individuales y colectivos que representan para ellos la penetración del conflicto armado en sus territorios (Fajardo, 1999).

\section{La Corte anota:}

El conflicto armado per se, por la manera como golpea a los pueblos indígenas del país, afecta en forma grave los derechos fundamentales de las personas que los conforman, especialmente sus derechos a la vida (art. 11, C.P.), a la integridad personal y a verse libres de tratos crueles, inhumanos y degradantes (art. 12, C.P.), a la dignidad personal (art. $1^{\circ}$, C.P.) y a la seguridad personal. Esta afectación es tan grave que, [...] se debe evaluar, por parte de las autoridades judiciales competentes, la posible comisión de violaciones serias del derecho internacional humanitario que conlleven consecuencias penales para sus perpetradores.
El desplazamiento forzado de los pueblos indígenas surte consecuencias especialmente graves sobre el goce efectivo de sus derechos fundamentales colectivos a la autonomía, la identidad y el territorio. Entre los distintos factores del desplazamiento forzado que conllevan una violación de estos derechos colectivos se encuentran la pérdida 0 el abandono del territorio tradicional, el desarraigo que rompe las pautas culturales directamente asociadas al territorio, el desplazamiento especialmente agudo de los líderes y autoridades tradicionales con sus necesarias secuelas sobre la integridad cultural, y en general la ruptura del tejido social causada por este crimen.

En el mismo auto se plantean una serie de medidas por adoptar que coadyuven en el propósito de superar el estado de cosas inconstitucional; este apartado plantea:

Diseñar e implementar, dentro de sus respectivas órbitas de competencia, un programa de garantía de los derechos de los pueblos indígenas afectados por el desplazamiento, con el nombre que los responsables gubernamentales estimen aconsejable ponerle [...] En el diseño de este programa se aplicarán los parámetros constitucionales de participación de las organizaciones que abogan por los derechos de los pueblos indígenas, así como de líderes de los pueblos indígenas más afectados por el desplazamiento.

Los planes de salvaguarda étnica han de contemplar los siguientes elementos mínimos: 1. Ha de ser debidamente consultado en forma previa con las autoridades de cada una de las etnias beneficiarias, de conformidad con los parámetros que ha señalado de manera reiterada la jurisprudencia constitucional para que la participación sea efectiva y respetuosa de la diversidad etnocultural. 2. Debe contener tanto un elemento de prevención del impacto desproporcionado del conflicto armado y del desplazamiento forzado sobre el pueblo indígena respectivo, como un elemento de atención efectiva y diferencial a las personas des- 
plazadas a la fecha. 3. Debe incluir un componente básico de protección de los líderes, autoridades tradicionales y personas en riesgo por sus posturas de activismo o de liderazgo. 4. Debe prever herramientas para el fortalecimiento de la integridad cultural y social de cada etnia beneficiaria. 5. Debe contener un ingrediente de protección de los territorios tradicionales, especialmente de los que están en proceso de titulación y asimismo de los que ya se encuentran titulados, frente a los distintos procesos bélicos y de despojo que se han descrito.

Por todo lo anterior la Corte resuelve:

DECLARAR que los pueblos indígenas de Colombia, según lo advertido en esta providencia, están en peligro de ser exterminados cultural o físicamente por el conflicto armado interno, y han sido víctimas de gravísimas violaciones de sus derechos fundamentales individuales $y$ colectivos y del derecho internacional humanitario, todo lo cual ha repercutido en el desplazamiento forzado individual o colectivo de indígenas.

DECLARAR que el Estado colombiano está en la obligación doble de prevenir las causas del desplazamiento forzado de los pueblos indígenas, y atender a la población indígena desplazada con el enfoque diferencial que para ello se requiere. En consecuencia, ORDENAR a los mismos funcionarios enunciados en el siguiente numeral que diseñen e implementen, dentro de sus respectivas órbitas de competencia, un programa de garantía de los derechos de los pueblos indígenas afectados por el desplazamiento, con el nombre que los responsables gubernamentales estimen aconsejable ponerle.

\section{REALIDAD DE LOS PUEBLOS INDÍGENAS EN BOGOTÁ}

Uno de los primeros informes que dan cuenta de la situación de los pueblos indígenas en la ciudad se publicó el año 2005 por la Fundación Hemera (Hemera, 2005), donde se realiza una caracterización de los pueblos que se encuentran en
Bogotá, exponiendo la situación socioeconómica que afrontaban para el año en que se realizó el estudio. Este arrojó el siguiente panorama:

La ciudad de Bogotá se ha configurado en un escenario de convivencia y apropiación territorial por parte de los pueblos indígenas, los cuales hacen presencia por tres razones principales, a saber: son pueblos originarios, migrantes o desplazados. Los originarios hacen referencia al pueblo Muisca asentado en las localidades de Bosa y Suba, cuyos territorios que hoy ocupan son producto de la herencia durante varias generaciones luego de la partición a la que se vieron sometidos los resguardos a finales del siglo XIX. La organización política actual gira en torno a la figura del cabildo, que si bien venía funcionando desde 1998, su institucionalización ocurrió el 3 de enero de 1999, lo cual permitió afianzar sus procesos identitarios como Muiscas (ONIC, 2010).

La categoría de migrantes se encuentra conformada por aquellos pueblos cuya presencia en la ciudad se debe a una motivación relativamente voluntaria para viajar de sus lugares de origen a la capital. Muchos de ellos vienen a Bogotá en busca de mejores alternativas para su vida; es decir, en sus lugares de origen no existen oportunidades de trabajo, lo que los lleva a tomar la decisión de acudir a las urbes en busca de actividades que les permitan generar un ingreso para sobrevivir. Por último, los desplazados se entienden a la luz del artículo $1^{\circ}$ de la Ley 387 de 1997, que reza acerca de la figura de desplazado:

[...] que se ha visto forzado a migrar dentro del territorio nacional abandonando su localidad de residencia o actividades económicas habituales, porque su vida, su integridad física, su seguridad o libertad personales han sido vulneradas o se encuentran directamente amenazadas, con ocasión de cualquiera de las siguientes situaciones:

Conflicto armado interno, disturbios y tensiones interiores, violencia genera- 
lizada, violaciones masivas de los derechos humanos, infracciones al derecho internacional humanitario u otras circunstancias emanadas de las situaciones anteriores que puedan alterar o alteren drásticamente el orden público.

Siguiendo como línea base el informe citado, este realiza descubrimientos significativos en cuanto a la percepción de bienestar y de vida de los pueblos indígenas, y su situación para entonces, destacando:

- Reconocimiento. Una de las esperanzas es la de lograr un reconocimiento por parte de la Administración Distrital y del resto de la ciudadanía. Desde allí se pueden construir los demás proyectos de vida. El reconocimiento implica no solo la aceptación de su presencia en la ciudad, sino de la consciencia de que son sujetos colectivos beneficiarios de una serie de derechos que no se ejercen en el papel sino en la vida cotidiana.

- Educación. Dado que ya hay generaciones nacidas en Bogotá y otros tantos jóvenes y niños que se vinculan a los espacios educativos en el Distrito, los indígenas esperan encontrar en las aulas espacios de convivencia y respeto por la diferencia. Producto de su propia experiencia, la ciudad no les ha brindado un espacio de formación escolar acorde con sus especificidades.

- Salud. No solo la vinculación a una ARS garantiza el reconocimiento del derecho a la salud. Además de ello, los indígenas esperan poder conciliar sus prácticas tradicionales de curación y sanción con las terapéuticas occidentales, no solo para beneficio propio como etnias sino entre ellos y los demás ciudadanos, quienes a su vez se pueden beneficiar de ello.

- Organización. Dado que los procesos organizativos a nivel de cabildo adquieren fuerza en esta administración por la iniciativa del alcalde para reconocerlos como tal, los indígenas esperan que el Distrito los apoye en el fortalecimiento administrativo y de gestión de su organización, con el fin de poder entablar canales de comunicación efectivos con las entidades y aprovechar los espacios dentro de los planes y proyectos de las instancias de acción distrital.

- Desarrollo económico y productivo. Si bien algunos grupos indígenas han logrado su inserción en la ciudad mediante el desarrollo de actividades económicas, ellos esperan apoyo por parte del distrito para fortalecer estas actividades, y detectar y promover otras tantas que sean posibles.

- Espacios de organización. Los nuevos procesos organizativos, y los ya iniciados, carecen de un espacio físico en el cual se puedan desarrollar. Los indígenas consideran que un gran aporte al fortalecimiento de las etnias es el de garantizarles un lugar donde puedan ejecutar sus actividades organizativas, educativas y culturales, no solo para el beneficio como grupo, sino para el de la ciudad, cuyos habitantes podrían tener un lugar dónde encontrarse con la diversidad.

\section{¿BOGOTÁ SIN INDIFERENCIA?}

En el marco de desarrollo de la política pública consolidada para el momento en el Plan de Desarrollo Distrital, Bogotá Sin Indiferencia. Un compromiso social contra la pobreza y la exclusión 2004-2008, tres ejes se caracterizan para realizar el análisis de la efectividad en cuanto a protección y disfrute de los derechos de los pueblos indígenas se trata. Estos son:

- Salud. La población indígena que no pertenece a un cabildo reconocido en Bogotá y que se encuentra en condición de desplazamiento reconocido por la RSS recibe atención en salud como población especial desplazada; se está empezando a trabajar en un enfoque diferencial de manera participativa con grupos de población desplazada indígena e instituciones. Sin embargo, sobre ello no hay claridad y en 
la realidad un indígena desplazado se cobija por los mismos programas que un desplazado no indígena, aunque la Red de Solidaridad Social y la Unidad de Atención Integral a la Población Desplazada tienen en sus bases de datos la variable "indígena" para clasificar la población, lo cual es un paso importante para el reconocimiento de la población y la aplicación de programas diferenciales. Para la población que no pertenece a un cabildo reconocido en Bogotá y que no se encuentra en condición de desplazamiento reconocido por la RSS, se viene realizando una gestión para el cruce de cuentas con algunas ARS y entidades territoriales de origen, y así los hospitales de la red pública realicen la facturación como población especial. Este proceso de gestión se propone que se estandarice a través de una ruta concertada con el nivel nacional, población indígena y entidades distritales, para garantizar el pago de la atención de las entidades de acuerdo con sus competencias, y para realizar procesos de educación y capacitación a funcionarios y población indígena. Para el proceso de salud pública la ruta es gratuita y universal (Hemera, 2005).

- Educación. La Secretaría de Educación tiene un registro de niños pertenecientes a grupos étnicos por institución educativa, dentro del que se destaca la presencia de niños Inga, Pijao, Kankuamo, Uitoto, Kametsa, Zenú, Wayuú, predominando los Pijao y los Kankuamo. Sin embargo, el registro no es muy preciso ya que así como hay niños con la pertenencia étnica directa (Kankuamo, Pijao...) hay otros donde solo aparece la palabra "indígena". Este esfuerzo por saber en el registro de matrícula la pertenencia étnica es importante para determinar la concentración y presencia de población indígena en las aulas escolares. En este escenario se han desarrollado ocho mesas de debate sobre políticas educativas de atención a grupos étnicos y perspectivas pedagógicas de abordaje. Se está trabajando en quince colegios un programa de desarrollo pedagógico con perspectiva étnica, con una inversión de $\$ 240.000 .000$ para los cuatro años de gobierno de la actual administración (Hemera, 2005).

- Desplazamiento. la Secretaría de Gobierno, el DABS, la Secretaría de Salud y la Secretaría de Educación están coordinando acciones con la Dirección de Asuntos Étnicos del Ministerio del Interior, para dar una atención adecuada a veintitrés familias con aproximadamente 105 personas de la comunidad Emberá Katío y Chamí, las cuales con recursos del Distrito fueron alojadas en un albergue temporal, y se coordina con las entidades del orden nacional para, previo reconocimiento de las condiciones adecuadas, lograr su retorno a los lugares de origen. El costo de atención de estas veintitrés familias asciende en septiembre de 2005 a \$60.322.355 (Hemera, 2005).

\section{PLAN DE DESARROLLO BOGOTÁ POSITIVA Y LAS POLITICAS PÚBLICAS PARA LOS PUEBLOS INDÍGENAS}

La Administración Distrital del Alcalde Samuel Moreno Rojas ha dispuesto el Plan de Desarrollo Bogotá Positiva: para vivir mejor, que en su artículo $1^{\circ}$ dispone:

Afianzar una ciudad en la que todas y todos vivamos mejor. En la que se mejore la calidad de vida de la población y se reconozcan, garanticen y restablezcan los derechos humanos y ambientales con criterios de universalidad e integralidad, convirtiéndose en un territorio de oportunidades que contribuya al desarrollo de la familia, en especial de los niños y niñas en su primera infancia. Una ciudad incluyente, justa y equitativa, en la que la diversidad y la interculturalidad sean una oportunidad, y la reconciliación, la paz y la convivencia sean posibles. Una ciudad cuya construcción sea el resultado de un proceso permanente de participación, en el que cada vez más personas se involucren en la discusión 
y decisión de los asuntos públicos. Una ciudad generadora de recursos y oportunidades, próspera y solidaria, competitiva y capaz de generar y distribuir equitativamente la riqueza. Una ciudad en la que todos y todas disfruten de los beneficios del desarrollo. Una ciudad responsable con el ambiente e integrada con su territorio circundante, con la nación y con el mundo. Una Bogotá positiva que cuente con unas finanzas sanas y una gestión pública efectiva, transparente, abierta a la participación ciudadana y con servicios cercanos a la ciudadanía.

De esta manera, la Administración ha concebido programas que propenden por la protección y el pleno disfrute de los derechos de los ciudadanos y las ciudadanas en la ciudad; tal es el caso del programa Bogotá respeta la diversidad, en el que se busca desarrollar e implementar las políticas públicas y los planes de acciones afirmativos orientados a reconocer y restablecer los derechos de los grupos religiosos, afrodescendientes, indígenas, rom y raizales, y de las lesbianas, gays, bisexuales y transgeneristas. Es así que Bogotá diversa pretende el fortalecimiento a lo largo de esta Administración de por lo menos cinco cabildos indígenas a través de acciones afirmativas, y acompañar y fortalecer siete agendas sociales de los procesos de comunidades negras, grupos religiosos, indígenas, pueblo rom, raizales. En el mismo sentido, por medio de su objetivo dos (2) "todos estudiando", se pretende garantizar preescolar para todos, al menos a partir de los 5 años, donde se debe aumentar a $41 \%$ la tasa de cobertura de atención en educación inicial, garantizando 41.900 cupos gratuitos en educación inicial para niños y niñas en primera infancia. La ampliación de cobertura en educación inicial se hará desde un modelo diferencial que garantice la inclusión de niñas, niños y adolescentes pertenecientes a diferentes grupos poblacionales como afrodescendientes, indígenas, rom.

\section{a. Economía y generación de ingresos}

El plan de desarrollo dispone desde sus ejes estructurales, en cuanto a los derechos económicos de los habitantes de la ciudad, de un programa denominado Alternativas productivas para la generación de ingresos, el cual pretende garantizar el derecho al trabajo con base en el desarrollo de las capacidades y potencialidades de la población, encaminado ante todo a generar mayores tasas de ocupación y por tanto a obtener una incidencia directa en los índices de desempleo de la población del distrito; atendiendo de igual manera el trabajo informal que se presenta en la ciudad, para obtener una disminución del mismo.

El ente encargado de la formulación y puesta en práctica de estos objetivos en el Distrito es la Secretaría de Desarrollo Económico, que ha desplegado una serie de programas dirigidos a la atención, apoyo y promoción en la generación de empleo e ingresos a personas pertenecientes a grupos étnicos. Estos programas poseen indicadores de cumplimiento y metas que permiten conocer el estado de avance en la evolución de sus políticas, como lo muestra la tabla a continuación:

Tabla 2.

\begin{tabular}{|l|l|}
\hline \multicolumn{1}{|c|}{ Programa } & \multicolumn{1}{c|}{ Meta } \\
\hline Banca Capital - microcréditos Banca Comunal & $\begin{array}{l}\text { Atender 174 unidades de negocio que cumplan con } \\
\text { las características del programa. }\end{array}$ \\
\hline
\end{tabular}




\begin{tabular}{|l|l|}
\hline \multicolumn{1}{|c|}{ Programa } & \multicolumn{1}{c|}{ Meta } \\
\hline $\begin{array}{l}\text { Apoyo a iniciativas de desarrollo empresarial y } \\
\text { formación para el trabajo - programas a la medida }\end{array}$ & $\begin{array}{l}\text { Apoyo de cuatro iniciativas de desarrollo empresa- } \\
\text { rial dentro de programas a la medida. }\end{array}$ \\
\hline $\begin{array}{l}\text { Apoyo a iniciativas de desarrollo empresarial y for- } \\
\text { mación para el trabajo - Apoyo a la promoción y ac- } \\
\text { ceso a mercados de la población afrodescendiente }\end{array}$ & $\begin{array}{l}\text { Apoyar una iniciativa productiva mediante la estra- } \\
\text { tegia de acceso a mercados. }\end{array}$ \\
\hline $\begin{array}{l}\text { Desarrollo tecnológico sostenible e innovación } \\
\text { y modernización de las actividades productivas. } \\
\text { Programa Red de Empresarios Innovadores }\end{array}$ & $\begin{array}{l}\text { Apoyo a seis unidades empresariales con potencial } \\
\text { exportador. }\end{array}$ \\
\hline $\begin{array}{l}\text { Idioma extranjero para población en edad de tra- } \\
\text { bajar. Talk to the World }\end{array}$ & Se contempla el acceso de 50 personas. \\
\hline $\begin{array}{l}\text { Implementación del plan maestro de abastecimien- } \\
\text { to y seguridad alimentaria de Bogotá }\end{array}$ & $\begin{array}{l}\text { Incorporar al plan maestro de abastecimiento } \\
\text { alimentario a 80 unidades empresariales para ser } \\
\text { capacitados. }\end{array}$ \\
\hline $\begin{array}{l}\text { Implementación del plan maestro de abastecimien- } \\
\text { to y seguridad alimentaria de Bogotá. PMASAB en } \\
\text { marco del plan maestro }\end{array}$ & $\begin{array}{l}\text { Fortalecer el acceso a mercados de los diferentes } \\
\text { productos que comercializan las comunidades } \\
\text { indígenas. }\end{array}$ \\
\hline $\begin{array}{l}\text { Proceso de formulación de la política pública para } \\
\text { comunidades indígenas }\end{array}$ & $\begin{array}{l}\text { Socialización, capacitación, construcción de pro- } \\
\text { puestas en torno a la política pública. }\end{array}$ \\
\hline
\end{tabular}

La Personería Distrital realizó una veeduría durante los primeros meses del año 2011 sobre el desarrollo de las políticas públicas para los grupos étnicos de la ciudad; consultó, entre otros grupos, a los pueblos indígenas que habitan la ciudad, por los proyectos ejecutados por la Secretaría de Desarrollo Económico (Personería Distrital, 2011). Los participantes no reconocieron los balances presentados por la entidad; por el contrario, plantearon la falta de conformación de empresas comunitarias al igual que la de proyectos productivos. Una de las dificultades que reconocen en este ámbito es la excesiva burocracia existente para acceder a uno que otro beneficio, pues a su juicio no existe un reconocimiento real de la población indígena radicada en Bogotá, haciendo que las vías de acceso a los subsidios que por ley deben entregarse no suplen a toda la población y desconoce la identidad cultural de los distintos pueblos antes que fomentarla. Esto se traduce en la baja valoración del conocimiento tradicional indígena, situación que lleva a la necesidad de encontrar otras maneras de generar recursos que aseguren su mínimo vital, así estas difieran a sus tradiciones (Personería Distrital, 2011).

Las organizaciones de los pueblos indígenas residentes en Bogotá le plantean a la Secretaría de Desarrollo Económico: 
Tabla 3.

\begin{tabular}{|l|}
\hline Facilitar proyectos a organizaciones o grupos indígenas. \\
\hline Que exista participación de los profesionales, técnicos, tecnólogos, en las entidades del Distrito. \\
\hline Crear una dependencia u oficina encargada de empleabilidad indígena. \\
\hline Crear un fondo de financiación que apoye a microempresarios y familias indígenas. \\
\hline Capacitación en elaboración y ejecución de proyectos productivos para indígenas desplazados. \\
\hline Las autoridades deberían estar ganando un sueldo. \\
\hline Reducir intermediarios para desplazados. \\
\hline Hacer censos de desplazados para pago de arriendo, salud, vivienda, mientras se soluciona. \\
\hline Exoneración de impuestos de valorización de las viviendas indígenas de nativos de Bogotá. \\
\hline Asignación de recursos económicos específicos para pueblos indígenas. \\
\hline Rendición de cuentas a los pueblos indígenas. \\
\hline
\end{tabular}

\section{b. Educación}

La Administración Distrital, a través de su Secretaría de Educación, ha puesto en marcha dos programas bandera, a saber: "Educación de calidad y pertinencia para vivir mejor" y "Acceso y permanencia a la educación para todas y todos". Dichos programas se encaminan a mejorar el desempeño académico de los colegios distritales y los resultados en las pruebas de evaluación, además del aumento de la matrícula oficial en los niveles preescolares, pri- maria, secundaria y media; estos esfuerzos están dirigidos a la reducción en la tasa de deserción escolar que se presenta en la ciudad. Dentro de estos programas se encuentran una serie de proyectos orientados a solventar las necesidades sentidas de los grupos étnicos en la ciudad, respondiendo desde sus particularidades, en la procura de fortalecer sus lazos culturales y preservar sus códigos de conducta y comportamiento.

A continuación se presentan los mencionados programas con las metas propuestas por cumplir:

Tabla 4.

\begin{tabular}{|l|l|}
\hline \multicolumn{1}{|c|}{ Programa } & \multicolumn{1}{|c|}{ Meta } \\
\hline $\begin{array}{l}\text { Convenio } 1010 \text { del } 27 \text { de noviem- } \\
\text { bre de } 2008\end{array}$ & $\begin{array}{l}\text { Aunar esfuerzos para el fortalecimiento de propuestas de atención } \\
\text { diferencial a población indígena en situación de desplazamiento. }\end{array}$ \\
\hline Convenio 1712 de 2009 & $\begin{array}{l}\text { Aunar esfuerzos para desarrollar procesos de acompanamiento } \\
\text { pedagógico con docentes y estudiantes sobre reconocimiento e } \\
\text { inclusión de los grupos indígenas con enfoque diferencial. }\end{array}$ \\
\hline
\end{tabular}




\begin{tabular}{|l|l|}
\hline \multicolumn{1}{|c|}{ Programa } & \multicolumn{1}{|c|}{ Meta } \\
\hline Convenio 1911 de 2009 & $\begin{array}{l}\text { Aunar esfuerzos para formar en competencias para la atención de } \\
\text { los conflictos, las estrategias de resolución y de habilidades para } \\
\text { la vida en comunidad. }\end{array}$ \\
\hline $\begin{array}{l}\text { Convenio } 1917 \text { de noviembre } \\
\text { de } 2009\end{array}$ & $\begin{array}{l}\text { Visibilizar aportes de la comunidad afro, por medio de personajes } \\
\text { afrocolombianos inspiradores para los estudiantes. }\end{array}$ \\
\hline Convenio 1101 de enero de 2010 & Fortalecer la red de jóvenes por la etnoeducación sankofa. \\
\hline Convenio 1067 de enero de 2010 & $\begin{array}{l}\text { Diseñar las bases de aprendizaje CEA para los ciclos 3, } 4 \text { y 5, y } \\
\text { apoyar la conmemoración del día nacional de la afrocolombiani- } \\
\text { dad. Acompañar 25 colegios en la transformación curricular para } \\
\text { incorporar la CEA al PEl. }\end{array}$ \\
\hline $\begin{array}{l}\text { Contrato } 995 \\
\text { Censibilizar y concientizar a los consejos directivos de la impor- } \\
\text { tancia de la CEA. }\end{array}$ \\
\hline $\begin{array}{l}\text { Convenio } 2009 \\
\text { de } 2009\end{array}$ & Diseñar y desarrollar programas contra el racismo y la discriminación. \\
\hline $\begin{array}{l}\text { Convenio } 1916 \text { de noviembre } \\
\text { de } 2009\end{array}$ & Fortalecer la capacidad de liderazgo de jóvenes afrodescendientes. \\
\hline $\begin{array}{l}\text { Convenio } 1086 \text { de julio } \\
\text { de } 2009\end{array}$ & Incentivar el trabajo que realizan los maestros sobre etnoeducación. \\
\hline $\begin{array}{l}\text { Convenio } 0990 \text { de junio } \\
\text { de } 2009\end{array}$ & $\begin{array}{l}\text { Diseñar las bases de aprendizaje CEA para los ciclos } 1 \text { y 2, y apoyar } \\
\text { la realización del seminario internacional: Diáspora Africana. }\end{array}$ \\
\hline
\end{tabular}

Los tres primeros programas se encuentran dirigidos particularmente a trabajar con las poblaciones indígenas en Bogotá, según los cuales se han podido lograr las metas contempladas hasta el momento, dando un $100 \%$ de cumplimiento a la atención diferencial a población indígena en situación de desplazamiento y al acompañamiento pedagógico con docentes y estudiantes sobre reconocimiento e inclusión de los grupos indígenas con enfoque diferencial. Los programas restantes tuvieron un cubrimiento particular en cuanto a la atención a las personas pertenecientes a las comunidades afrodescendientes; cabe resaltar que en este momento no se tienen reportes de programas dirigidos de manera diferencial a los pueblos romo raizales, hecho que se analizará más adelante.

En cuanto a la comunidad afrodescendiente, el nivel de avance en los distintos programas registrados hace referencia a un alto nivel de cumplimiento en cuanto a las metas proyectadas, consolidadas por medio de salidas pedagógicas, cine-foros, talleres para desarrollar habilidades artísticas, investigativas sobre la cultura afrocolombiana, al igual que talleres, reuniones y seminarios con los maestros a través de los cuales se fomenta investigar, organizar y sistematizar las bases del aprendizaje CEA. En cumplimiento de los programas, se 
han llevado a cabo seminarios de sensibilización y concientización en CEA y el diseño de piezas publicitarias y estrategias pedagógicas contra el racismo y la discriminación.

Todas las acciones reportadas se encaminan al empoderamiento y la integración del componente étnico en el sistema educativo, traducido en talleres sobre liderazgo para jóvenes afrocolombianos estudiantes del Distrito y en la selección de diez experiencias significativas en etno-educación que permiten la consolidación del componente étnico afro como un referente en las experiencias del Distrito en términos educativos. Los procesos de sensibilización han sido de la mayor preocupación desde la Secretaría, tanto a maestros como a directivos para que sean agentes que reproduzcan las experiencias significativas y la inclusión en la diferencia.

La percepción de los pueblos indígenas en el Distrito es de crítica al hecho que en los colegios a los cuales asisten sus niños y niñas no existen profesores indígenas, traduciéndose en la ausencia de una educación propia para ellos, una que conserve el acervo cultural a través de las tradiciones, la lengua, los usos y costumbres de los distintos pueblos como una forma de supervivencia y de socialización de sus lazos y códigos de comportamiento, tanto en sus relaciones sociales como en su vínculo con la naturaleza (Personería Distrital, 2011).

La participación educativa es diezmada como resultado de las pocas posibilidades de acceso que tienen a ella; sostienen los participantes que no hay facilidad alguna para el acceso a la educación superior, ya que la reducida oferta de convenios y becas, por ejemplo, dificultan el ingreso de sus miembros a estos servicios, más aún cuando estos últimos no los utilizan indígenas sino que se asignan a otras personas. Hacen hincapié en la no existencia de universidades indígenas, ni clases, cátedra o facultades indígenas que remarquen la cosmovisión y transmitan el conocimiento tradicional de los pueblos. Como consecuencia, plantean las siguientes recomendaciones:

Tabla 5.

\begin{tabular}{|l|}
\hline Otorgar mayor número de becas para los indígenas en los jardines, colegios y universidades. \\
\hline Que no existan limitaciones de cupos. \\
\hline Que existan recursos específicos para la educación de los pueblos indígenas. \\
\hline Control y seguimiento a los recursos destinados a los indígenas. \\
\hline Que se tengan en cuenta los estudios para los cupos internacionales. \\
\hline Convenios con colegios privados para pueblos indígenas. \\
\hline Becas completas que incluyan: alojamiento, alimentación, estudio y otros gastos educativos. \\
\hline Fomentar aulas o infraestructura para la educación de cada pueblo, que generen el rescate de su lengua. \\
\hline
\end{tabular}

\section{Salud}

La Secretaría de Salud del Distrito, encaminada a garantizar el derecho a la salud, y a través de su acceso efectivo y sin discriminación alguna a los habitantes de la ciudad, ha planteado dos programas marco que permitan, a través de acciones concretas, dar respuesta a las necesidades de la población, en especial aquella considerada como vulnerable. Tales programas son: Bogotá Sana y 
Garantía del aseguramiento y atención en salud. El primero de ellos tiene como meta estructural avanzar en el cumplimiento de las metas de los Objetivos de Desarrollo del Milenio relacionadas con: mortalidad infantil y materna; el segundo busca aumentar la población afiliada al sistema de seguridad social en salud. Ambos programas se encuentran inscritos en el capítulo "Ciudad de derechos" del plan de desarrollo Bogotá Positiva.

Pese al esfuerzo de la Personería Distrital al solicitar información sobre los programas, metas y resultados de las políticas de salud dirigidas a los pueblos indígenas, no se obtuvo respuesta.

En cuanto a lo positivo en los servicios de salud que se prestan en la ciudad y la manera como estos coadyuvan en la protección de los derechos de los distintos pueblos indígenas que residen en ella, se valora como bueno que existan algunas campañas de prevención y vacunación por parte de la Secretaría, al igual que la intención de unificar todos los miembros de los pueblos indígenas en una IPS, hecho que facilitaría el acceso al servicio y el trato diferenciado en cuanto a las necesidades específicas de esta población.

En esta misma línea se observa que algunos hospitales dan la participación a los médicos tradicionales, permitiendo el refuerzo cultural de sus costumbres y la toma de sentido de su cosmovisión, para que de esta manera los lazos culturales y las formas de entender el mundo persistan en un contexto diferente. Por esto se reconoce que aunque la atención en salud es baja, existe, y eso es algo que se debe valorar, no sin antes manifestar las deficiencias evidentes del servicio.

Es aquí donde los pueblos manifiestan que aunque existe servicio de salud, este es de muy mala calidad, y los programas de promoción y prevención no se consultan con los pueblos indígenas para mirar los perfiles epidemiológicos propios diferenciados. Tampoco existen programas para nutrición a mujeres gestantes, menores de edad, discapacitados o tercera edad, que son los más afectados por encontrarse en la ciudad, y su grado de vulnerabilidad es mayor frente al entorno que los rodea; esto se agrava cuando no hay carnetización para los pueblos indígenas desplazados y no desplazados, ya que sus necesidades varían y la atención, que debe ser integral, también debe ser diferenciada para suplir y satisfacer lo que requiere cada situación.

Algo importante que manifestaron los participantes es que los proyectos agroecológicos no se tienen en cuenta con las comunidades, como contar con un territorio para las medicinas de cada pueblo, lo que permitiría fortalecer la labor de sus médicos tradicionales y la socialización de su conocimiento ancestral. Proponen a este respecto:

Tabla 6.

Construcción de malocas tradicionales para la atención de las comunidades indígenas en Bogotá.

Consecución de terreno para el cultivo de plantas medicinales.

Atender y hacer cumplir las normas que establece la Constitución en lo que tiene que ver con la comunidad indígena.

Interrelacionar la medicina tradicional con la medicina occidental.

Fijar salario a los médicos tradicionales.

Conformación de una IPS indígena.

\section{d. Vivienda}

La Administración Distrital, por intermedio de la Secretaría de Hábitat, ha puesto en marcha un programa denominado Derecho a un techo, en el que se busca reducir el déficit cualitativo y cuantitativo de vivienda en la ciudad. Para esto ha desarrollado unas acciones, a continuación referenciadas con sus respectivas metas: 
Tabla 7.

\begin{tabular}{|l|l|}
\hline \multicolumn{1}{|c|}{ Programa } & \multicolumn{1}{c|}{ Meta } \\
\hline $\begin{array}{l}\text { Subsidio distrital de } \\
\text { vivienda } 2009\end{array}$ & $\begin{array}{l}\text { Vivienda para comu- } \\
\text { nidades indígenas }\end{array}$ \\
\hline $\begin{array}{l}\text { Subsidio distrital de } \\
\text { vivienda } 2010\end{array}$ & $\begin{array}{l}\text { Vivienda para comu- } \\
\text { nidades indígenas }\end{array}$ \\
\hline $\begin{array}{l}\text { Subsidio distrital de } \\
\text { vivienda } 2009\end{array}$ & $\begin{array}{l}\text { Vivienda para afro- } \\
\text { descendientes }\end{array}$ \\
\hline $\begin{array}{l}\text { Subsidio distrital de } \\
\text { vivienda } 2010\end{array}$ & $\begin{array}{l}\text { Vivienda para afro- } \\
\text { descendientes }\end{array}$ \\
\hline
\end{tabular}

Como se puede observar, los pueblos indígenas y las comunidades afrodescendientes tienen un capítulo especial de trabajo dentro de los proyectos que se plantean desde la Secretaría, pero como se volvió recurrente, tanto el pueblo rom como los raizales se encuentran marginados de estos beneficios de apoyo. De los avances reportados encontramos que, para los pueblos indígenas en 2009, la Secretaría Distrital de Hábitat asignó siete subsidios por valor de \$ 83.479.200 y no desembolsó ninguno, y Metrovivienda asignó diecisiete y desembolsó seis por un valor de $\$ 72.312 .500$; para 2010, la Secretaria de Hábitat asignó nueve y desembolsó uno por un valor de \$12.422.500, Metrovivienda no asignó pero desembolsó $\$ 337.267 .500$ del año anterior.

Por estas razones, las organizaciones de los pueblos indígenas recomiendan:

Tabla 8.

Acceder a viviendas para que sean más cercanas.

El crédito para vivienda debe ser para vivienda que garantice cercanía.

\section{e. Derechos políticos: gobierno - participación}

Uno de los ámbitos de mayor preocupación e interés por parte de la actual Administración Distrital ha sido la creación de espacios de participación y reconocimiento político de los grupos étnicos en la ciudad. Este reconocimiento se encamina a generar condiciones en las que se protejan los derechos políticos de las personas pertenecientes a los diferentes grupos, planteando proyectos y programas en los que se encuentran: Bogotá respeta la diferencia, Ahora decidimos juntos, Redes sociales y Control social al alcance de todas y todos. Estos programas están constituidos por una serie de metas que denotan las estrategias por desarrollar a lo largo del periodo, en el cual se buscan adoptar e implementar políticas étnicas en el marco de Bogotá respeta la diferencia, disminuir las violencias por orientación sexual e identidades de género; también Bogotá Positiva trabaja en la implementación del sistema distrital de participación, en conexión con el aumento de las instancias de participación y las organizaciones sociales que se articulan en torno a intereses comunes de ciudad.

Por último, en aras de la transparencia en cuanto a la inversión de los recursos y la eficiencia de la misma en la protección de los derechos de las personas pertenecientes a grupo étnicos, se propuso un proyecto para generar condiciones que hagan efectivo el control social, donde se observen ejercicios prácticos al respecto en la gestión pública distrital.

Del trabajo realizado con los beneficiarios de estos programas descritos se desprende una calificación positiva; a nivel general, hay una visualización en torno a los pueblos indígenas en el escenario público e institucional de la ciudad, incluyendo indígenas como funcionarios en las instituciones de la Administración Distrital, con la posibilidad de acceder a espacios de trabajo por sus comunidades y ser escuchados en la construcción de estrategias de intervención que satisfagan las necesidades que presentan. Es importante resaltar que la inclusión de funcionarios de grupos étnicos en la Administración Distrital obedece al derecho 
a la igualdad y no discriminación (de carácter individual), pero no agota el derecho colectivo a la participación en la toma de decisiones del Estado.

El Distrito ha facilitado espacios sociales e interinstitucionales en los que participan miembros de los pueblos indígenas por medio de convocatorias en las que han estado presentes tanto instancias del ámbito distrital como nacionales decisorias en cuanto a la creación de condiciones de la protección de los derechos de estos pueblos (ej. Defensoría del Pueblo).

Es como resultado del trabajo realizado, con la participación de representantes de los diferentes pueblos y funcionarios de las entidades con capacidad de decisión, que se implementaron programas y proyectos en beneficio de la población indígena en Bogotá, como lo es la constitución de malocas, la atención integral de la población en situación de desplazamiento por intermedio del IPES y de la Dirección de derechos humanos y apoyo a la justicia de la Secretaría de Gobierno.

Aunque se hicieron importantes esfuerzos que los mismos beneficiarios reconocen, también evidencian una serie de deficiencias que consideran determinantes en el camino de garantizar el efectivo disfrute de los derechos políticos. La importancia de la garantía plena de estos derechos reside en que es desde estos espacios de participación, construcción de la política y estrategias de ejecución, en los que se materializan las disposiciones de protección, fortalecimiento y conservación de la cultura indígena. Es aquí donde el empoderamiento del conocimiento cultural y de las condiciones reales de los miembros de este grupo étnico pueden encontrar una vía de acceso en pro del bienestar común de aquellos que por una u otra razón han terminado en Bogotá.

Dicho esto, los beneficiarios indígenas expresan que no existe política pública indígena, y si esta existe no se construye con la población étnica; en otras palabras, los procesos de participación para la construcción de esta política ha sido deficiente en sus pretensiones y en la manera en que se viene desarrollando, puesto que una de las mayores quejas es la ausencia de voluntad política para poder consolidarla. Esto puede resultar paradójico al considerar lo que se debe reconocer: la creación de espacios de participación en la ciudad.

Esta aparente paradoja puede explicarse desde la evaluación de la calidad de la participación y de las determinaciones que se toman como resultado de la misma, puesto que los participantes del grupo focal anotan que el Distrito solo da participación presencial, formal, pero que no trasciende los espacios en los que se realizan las reuniones y mucho menos se refleja en las decisiones políticas que se concretan. Sin embargo, es necesario reconocer los esfuerzos de IDPAC en esta área, aunque son insuficientes, dado que ellos propician los procesos. Además, por un lado, la voluntad política para tomar decisiones está en otras instancias distritales y, por el otro, la falta de unidad de los distintos grupos indígenas en el Distrito se convierte en factor determinante en los retrasos del desarrollo de procesos participativos.

Sumado a esto, los mecanismos de participación se leen como un monopolio del Distrito donde se convocan pocas personas (no sienten que haya representatividad entre quienes participan) y siempre son las mismas quienes asisten a estos procesos, trayendo como resultado la no construcción compartida de las propuestas y de consenso con los miembros de los pueblos.

Los indígenas están preocupados porque perciben que en el Distrito existen fuertes brotes de violencia y discriminación contra sus pueblos, situación que debe atenderse con prontitud y eficiencia a través de trabajo institucional y educación ciudadana.

Descrito este panorama, los pueblos indígenas proponen: 
Tabla 9.

Restauración de territorio a los pueblos indígenas por sus culturas.

Participación en la toma de decisiones en cualquier mesa política.

Tener en cuenta a los profesionales de los pueblos indígenas ante las instituciones y entidades del gobierno.

Mayor participación en alcaldías locales.

Verdadera participación en el tema de las consultas: que sean previas y no cuando ya estén hechos los proyectos. Consultas reales.

Más control de los recursos destinados a los pueblos indígenas. Control a alcaldías y entidades.

\section{EL ACUERDO 359 DE 2009, UN AVANCE QUE SE QUEDÓ A MEDIO CAMINO}

La Constitución de 1991 avanza lentamente en superar el abismo en que han vivido nuestros pueblos indígenas durante más de 500 años; este lento proceso se ha ido materializando en la creación y desarrollo de políticas públicas y acciones afirmativas. En el caso de Bogotá, a pesar de los avances señalados anteriormente, solo hasta la expedición de este acuerdo se puede decir que inicia la creación de una verdadera política pública de la administración municipal para la garantía, promoción y restablecimiento de los derechos de los pueblos indígenas que habitan la ciudad.

Este instrumento, "Por el cual se establecen los lineamientos de política pública para los indígenas en Bogotá, D.C., y se dictan otras disposiciones", se reconoció como uno de los principales logros para los pueblos indígenas que habitan la ciudad, ya que establece la necesidad de implementar acciones afirmativas.

Son políticas o medidas dirigidas a favorecer a determinadas personas 0 grupos, ya sea con el fin de eliminar o reducir las desigualdades de tipo social, cultural o económico que las afectan, bien de lograr que los miembros de un grupo sub-representado, usualmente un grupo que ha sido discriminado, tengan una mayor representación,

para garantizar y restablecer los derechos de los pueblos indígenas que habitan en el D.C.

Igualmente, en su artículo $3^{\circ}$ establece:

Defínase por lineamientos de política pública para los indígenas, en Bogotá, D.C., el conjunto de estrategias, acciones, planes y programas que la Administración Distrital en todos sus órdenes desarrollará en concertación con los pueblos indígenas, para garantizar igualdad de oportunidades, acceso y permanencia en el goce efectivo de sus derechos y el mejoramiento de sus condiciones de vida.

Para los fines del presente acuerdo se adoptarán, además de las aquí contempladas, las definiciones y fundamentos contenidos en los acuerdos, protocolos y tratados internacionales en relación con población indígena, firmados por Colombia, así como las demás normas que rigen esta materia.

Esta nueva política pública estará en cabeza del mismo Alcalde de la ciudad, según lo dispone el artículo $4^{\circ}$ :

Todas las acciones de la Administración Distrital que tengan relación con los indígenas en Bogotá, D.C., estarán reguladas por una política pública, cuya formulación será de competencia del Alcalde Mayor quien la concertará con los indígenas en Bogotá, D.C., a través de sus autoridades y organizaciones.

Igualmente importantes son los principios sobre Ios cuales la Administración Distrital orientará la política a favor de los pueblos indígenas, establecidos en el artículo 5०: "Diversidad e integridad étnica y cultural, interculturalidad y multiculturalidad, representación colectiva, autonomía, participación, consulta y concertación, equidad étnica". 
Los lineamientos de la política acogen de manera generosa los preceptos de la Constitución de 1991 y permiten generar una acción coordinada interinstitucional del Distrito Capital:

6.1. Fortalecimiento de la identidad cultural y ejercicio de derechos de los pueblos indígenas en el Distrito Capital y mejoramiento de sus condiciones de vida.

6.2. Garantía de atención oportuna e integral, con enfoque diferencial, a la población indígena en situación de desplazamiento forzado por la violencia, en responsabilidad compartida con el Gobierno Nacional.

6.3. Promoción de relaciones de entendimiento intercultural entre los indígenas y el conjunto de la población bogotana.

6.4. Promoción de Bogotá, D.C., como ciudad multiétnica e intercultural, incluyente de todos los grupos culturales y sociales con identidades indígenas particulares. Una ciudad solidaria y respetuosa de la diversidad.

6.5. Erradicación de prejuicios, estereotipos y prácticas sociales y simbólicas de discriminación e inequidad hacia los indígenas, por razón de su etnicidad.

6.6. Reconocimiento y apoyo a las iniciativas de los pueblos indígenas, relacionadas con la acción política no violenta, la resistencia civil y la solución política al conflicto armado.

6.7. Promoción de relaciones de corresponsabilidad social, transparencia y confianza entre el Distrito Capital y las autoridades y organizaciones indígenas.

6.8. Garantías para el funcionamiento de los cabildos indígenas, en su calidad de entidades públicas de carácter especial que cumplen funciones administrativas, legislativas y jurisdiccionales en sus asuntos comunitarios.

Sin embargo, a tres años de la aprobación del Acuerdo 359 aún no se ha reglamentado el programa de acciones afirmativas para las comunidades y miembros de los pueblos indígenas que habitan en el Distrito Capital.
Los pueblos indígenas de Colombia y los que viven en Bogotá aún esperan, no con muchas esperanzas, que la Constitución de 1991 se materialice en políticas públicas y acciones afirmativas, ya que de lo contrario esa utopía en la que todos soñamos, y vimos reflejada en la Constitución hace 20 años, se puede convertir en una "maloca vacía", como dice nuestro querido líder indígena Gerardo Jumi.

\section{CONCLUSIONES PARCIALES}

1. Los desarrollos formales en la defensa y promoción de los derechos de los pueblos indígenas son realmente importantes. Los derechos proclamados en la Constitución de 1991 marcaron una luz de esperanza sobre estos pueblos históricamente marginados, discriminados y excluidos.

2. Una rica y generosa jurisprudencia de la Corte Constitucional colombiana ha señalado de manera clara los contenidos materiales de los derechos de los pueblos indígenas; sin embargo, este hecho no significa que tales fallos sean finalmente acatados por las entidades del Estado que tienen a su cargo dichas competencias.

3. Son las políticas públicas, los planes y programas los que realmente permiten hacer un balance de los veinte (20) años de la Constitución Política de Colombia respecto de los actores sociales. En este sentido, en relación con los derechos de los pueblos indígenas, el balance no es positivo, máxime si se tiene en cuenta la grave crisis social y humanitaria de nuestros pueblos indígenas, de la cual la misma Corte Constitucional ha sido insistente. Solo después de veinte años se inició el proceso de incorporación de los preceptos constitucionales en los planes de desarrollo municipales (caso Bogotá), que permiten una asignación presupuestal clara y exclusiva para la creación de planes y programas que garanticen y restablezcan los derechos de estas comunidades.

4. La tarea apenas comienza para la administración municipal del Distrito Capital; una vez 
aprobado el Acuerdo 359 de 2009 falta aún la aprobación del Plan de Acciones Afirmativas, que defina de manera puntual los recursos del Distrito asignados para unificar y crear una verdadera política pública para los pueblos indígenas que habitan el Distrito Capital.

\section{REFERENCIAS}

Abramovich, V. y Pautassi, L. (2010). La medición de los derechos en las políticas sociales. Buenos Aires: Editoriales del Puerto.

Ariza Santamaría, R. (2010). Los derechos humanos en América Latina, una promesa sin cumplir. En Diálogo Político, 4. Buenos Aires.

Carvajal Martínez, J.E. (2008). Seguridad dentro del estado de garantías. Bogotá: ILSA.

Cepeda Espinosa, M.J. (2009). Auto 004 de la Sentencia T-025. Corte Constitucional Colombiana.

Comisión Interamericana de Derechos Humanos. (2009). Informe anual. Washington.

Concejo de Bogotá. (2009). Acuerdo 359.

De Sousa Santos, B. y García Villegas, M. (2001). Colombia: el revés del contrato social de la modernidad. En El caleidoscopio de las justicias en CoIombia. Bogotá: Colciencias, Instituto Colombiano de Antropología e Historia, Universidad de Coimbra - CES, Universidad de los Andes, Universidad Nacional de Colombia, Siglo del Hombre Editores.

Escuela de Formación en Desplazamiento Forzado. (2007). Memorias. En Desplazamiento forzado en Colombia. Derechos, acceso a la justicia y reparaciones. Bogotá.

Fajardo Sánchez, L.A. (1998). Manuel Quintín Lame y los guerreros de Juan Tama. Madrid, España: Madre Tierra Editores.
Fajardo Sánchez, L.A. (1998). Multiculturalismo y derechos humanos - una perspectiva desde el pueblo indígena Wiwa de la Sierra Nevada de Santa Marta. Bogotá.

Fajardo Sánchez, L.A. (1999). El derecho internacional humanitario y los pueblos indígenas de la Sierra Nevada de Santa Marta. Oficina del Alto Comisionado para la Paz. Colección sobre DIH.

Fajardo Sánchez, L.A. y García Lozano, L.F. (2010). Utopía y jurisprudencia constitucional. Universidad Santo Tomás.

Fajardo Sánchez, L.A., García Lozano, L.F. y Abondano Lozano, C. (2007). Los invisibles y la lucha por el derecho en Colombia. Bogotá: Universidad Santo Tomás.

Fundación Hemera. (2005). Diagnóstico de grupos indígenas en Bogotá y lineamientos de política pública para la atención de grupos étnicos. Bogotá.

Organización de Estados Americanos. Convención Interamericana de Derechos Humanos. San José de Costa Rica.

Organización de las Naciones Unidas. (2004, noviembre 10). Informe del Relator Especial sobre la situación de los derechos humanos y las libertades fundamentales de los indígenas, Sr. Rodolfo Stavenhagen. E/CN.4/2005/88/Add.2.

Organización de las Naciones Unidas. (2007). Declaración Universal de los Derechos de los Pueblos Indígenas.

Organización de las Naciones Unidas. (2007, septiembre 13). Resolución aprobada por la Asamblea General.

Organización de las Naciones Unidas. (2010, enero 8). La situación de los pueblos indígenas en 
Colombia: seguimiento a las recomendaciones hechas por el relator especial anterior. Sr. James Anaya. A/HRC/15/34/.

Organización Internacional del Trabajo. Convenio 169. Ginebra.

Organización Nacional Indígena de Colombia ONIC. (2010). Informe Anual. Bogotá.
Personería de Bogotá. (2011). Veeduría sobre políticas públicas para los grupos étnicos que habitan el Distrito Capital. Informe Final.

Semper, F. (2007). Los derechos de los pueblos indígenas de Colombia. UNAM: Instituto de Investigaciones Jurídicas. Revisado en http://www. juridicas.unam.mx/publica/librev/rev/dconstla/ cont/20062/pr/pr3.pdf 